\title{
CORRESPONDENCE
}

\author{
PTERYGIUM
}

To the Editors of the BRITISH Journal OF OPHTHALMOLOGY

DEAR SIRS-Several books on ophthalmic surgery have appeared since Kamel described his method of dealing with pterygia (British Journal of Ophthalmology, $9,549,1946$ ) but, as far as I am aware, in none is his procedure mentioned. In Cornwall, where pterygia are not uncommon, a number have been dealt with by the Kamel method with good result. As this procedure is simpler and apparently more effective than the transplanting methods still advocated, it would be interesting to know whether there is some objection to it, or otherwise why it has been ignored.

Yours faithfully,
WoOdside, WeStern Terrace,
C. Heath.
FALMOUTH.

March 27, 1952.

\section{ORBITAL IMPLANTS}

To the Editors of the British Journal OF OPHTHALMOLOGY

DeAR Sirs-D. P. Choyce in his article "Orbital Implants" (British Journal of Ophthalmology, 36, 123, 1952) points to the advisability of using totally buried tantalum or acrylic implants, and concludes by saying that an effort should be made to develop an acrylic implant which would have the advantage of economy. His references to the literature do not include relevant articles by Ellis (1949), and Allen and Allen (1950), describing similar buried acrylic implants.

A few of these implants made by a dental mechanic to the specification of Allen and Allen have been used in the Birmingham and Midland Eye Hospital with satisfactory results. A case was shown at a meeting of the Midland Ophthalmological Society in December, 1951, in which movement of the prosthesis appeared to be full, although there was a $3^{\circ}$ lag before the artificial eye began to move; this was followed by $15^{\circ}$ comitant movement to right and left, after which more marked lagging occurred.

It would appear that implants of the type suggested by Allen and Allen would provide satisfactory movement for cosmetic purposes and could be used as a routine at excision. A small number for use in individual centres could quite easily be made by a dental mechanic, but an effort is being made here to have them manufactured cheaply on a larger scale.

\section{Yours faithfully,}

\section{1, Calthorpe Road, EdgBaston, Birmingham, 15.} M. J. ROPER-HALl.

March 21, 1952.

\section{REFERENCES}

Allen, J. H., and Allen, L. (1950). Arch. Ophthal., Chicago, 43, 879. Ellis, O. H. (1949). Amer. J. Ophthal., 32, 990. 